\title{
PEMANFAATAN ARANG AKTIF DARI TONGKOL JAGUNG (Zea Mays L.) SEBAGAI ADSORBEN ZAT WARNA SINTETIS UNGU
}

\author{
Eka Purnamawati, Ruslan*, Agrippina Wiraningtyas dan Arif Munandar \\ Email: ruslanabinada@gmail.com
}

\begin{abstract}
ABSTRAK
Pada penelitian ini akan dibuat arang aktif dari tongkol jagung dan diaktivasi secara fisika dan kimia dengan aktivator $\mathrm{HCl}$. Proses karbonasi dilakukan pada suhu $360^{\circ} \mathrm{C}$ selama 1 jam dilanjutkan dengan proses aktivasi fisika pada suhu $150{ }^{\circ} \mathrm{C}$ selama 2 jam aktivasi kimia menggunakan $\mathrm{HCl}$ direndam selama $24 \mathrm{jam}$. Hasil penelitian ini menentukan daya adsorpsi dilakukan dengan penambahan serbuk arang dengan variasi massa adsorben mulai 0;0,2; 0,4; 0,6; 0,8 dan 1,0 gram kedalam larutan zat warna sintestis ungu dan diukur dengan menggunakan spektrofotomer UV-Vis dengan rentang panjang gelombang 190 - 750. Pada variasi massa adsorben terbukti bahwa semakin banyak serbuk arang aktif yang digunakan maka daya serapnya semakin besar pada zat warna sintetis orange panjang gelombang maksimum $\lambda_{\text {maks }} 493 \mathrm{~nm}$ dengan nilai adsorbansi $(A=0,082)$.
\end{abstract}

Kata Kunci : arang aktif, tongkol jagung, adsorben, zat warna sintetis ungu

\section{PENDAHULUAN}

Tongkol jagung merupakan salah satu limbah pertanian yang sangat potensial dimanfaatkan untuk dijadikan arang aktif, karena limbah tersebut sangat banyak dan terbuang percuma (Bharathi, 2013). Pada bahan ini terdapat kandungan unsur karbon $43,42 \%$ dan hidrogen $6,32 \%$ dengan nilai kalornya berkisar antara 14,7-18,9 MJ/kg. Selama ini masyarakat cenderung memanfaatkan limbah tongkol jagung hanya sebagai bahan pakan ternak, bahan bakar atau terbuang percuma. Untuk menghindari hal ini perlu adanya pemanfaatan limbah tongkol jagung tersebut, salah satunya yaitu sebagai bahan baku arang aktif. Arang dari tongkol jagung didapatkan dari hasil karbonasi (pembakaran), tongkol jagung dibakar pada suhu $360^{\circ} \mathrm{C}$ secara merata setelah terbakar arang dipisahkan dari abu. Perlakuan diberikan terhadap arang yang bertujuan untuk memperbesar pori. Dalam proses pembuatan arang aktif yang bertujuan untuk membuka, menambah atau mengembangkan volume pori dan memperbesar diameter pori yang telah terbentuk pada proses karbonisasi. Melalui proses aktivasi arang aktif akan memiliki daya adsorpsi yang semakin meningkat, karena arang aktif hasil karbonisasi biasanya masih mengandung zat yang masih menutupi pori-pori permukaan karbon aktif. Pada proses aktivasi arang aktif akan mengalami perubahan sifat, baik fisika maupun kimia sehingga dapat berpengaruh terhadap daya adsorpsi (Budiono, 2010).

Arang aktif merupakan suatu padatan yang dihasilkan dari bahan-bahan yang mengandung karbon dengan pemanasan pada suhu tinggi maupun diaktifasi dengan bahanbahan kimia (aktifator). Arang aktif dapat dibuat dari arang hasil pembakaran biomassa dari tanaman seperti tempurung kelapa (Pambayun, 2013), kelapa sawit (Purwanto, 2011) limbah kayu jati (Sudarja, 2012) dan tongkol jagung. Arang aktif adalah arang yang sudah mengalami aktivasi, sehingga luas permukaanya menjadi lebih besar karena jumlah porinya lebih banyak. Arang aktif memiliki struktur amorf dengan luas permukaan 300-2000 m²/gr (Surest, 2015). Arang aktif disusun oleh atom-atom karbon yang terikat secara kovalen 
dalam kisi heksagonal yang amorf dan berupa pelat datar. Pelat-pelat ini bertumpuk satu sama lain dengan gugus hidrokarbon pada permukaannya. Perlakuan dengan menghilangkan hidrogen dari gugus hidrokarbon, permukaan dan pusat arang aktif menjadi luas (Ruslan, 2013).

Dalam industri tekstil, zat pewarna merupakan salah satu bahan baku utama. Sekitar $10-15 \%$ dari zat warna yang sudah digunakan tidak dapat dipakai ulang dan harus dibuang. Zat pewarna dari industri tekstil tersebut merupakan zat pewarna senyawa organik dari jenis procion,erionyl, auramine yang diketahui sangat sulit untuk didegradasi secara alami. Oleh karena ini, beberapa penelitian mencoba mengembangkan proses adsorbsi sebagai alternatif dalam pengolahan limbah cair industri tekstil menggunakan adsorben yang lebih ekonomis (Ruslan, 2013). Beberapa metode konvensional telah dilakukan untuk menanggulangi masalah limbah pewarna, seperti oksidasi, koagulasi dan flokulasi, adsorpsi dan pertukaran ion.

Salah satu metode yang efektif untuk memisahkan zat warna dari limbah adalah dengan metode adsorpsi. Selain dari pemilihan Metode adsorpsi, faktor lain juga yang mempengaruhi adsorpsi memiliki kelebihan dari metode yang lain karena prosesnya yang lebih sederhana, biayanya relatif murah, ramah lingkungan (Patel, 2008). Berdasarkan paparan di atas penelitian ini tentang Pemanfaatan arang aktif dari tongkol jagung sebagai adsorben zat warna sintetis wantex ungu dengan menggunakan spektrofotometer UV-Vis.

\section{METODE}

\section{Alat dan Bahan Penelitian}

Adapun alat dan bahan yang digunakan dalam penelitian ini adalah sebagai berikut: Alat yang digunakan dalam penelitian ini adalah Baskom, pisau, drum, oven, gelas kimia, blender, neraca analitis, desikator, labu ukur, tabung reaksi, rak tabung reaksi, erlemeyer, kertas saring, magnetic stirrer, aluminium foil, termometer, kertas saring, ayakan, spektrofotometer UV-Vis. Bahan yang digunakan dalam penelitian ini adalah tongkol Jagung, zat warna sintetis ungu, $\mathrm{HCl} 1 \mathrm{M}$, aquades.

\section{Prosedur Penelitian \\ Preparasi Sampel}

Tongkol jagung dipotong menjadi bagian-bagian kecil kemudian dicuci dengan air mengalir selama 20 menit untuk menghilangkan partikel- partikel pengotor yang melekat pada permukaan tongkol jagung kemudian dikeringkan dibawah sinar matahari selama 3 hari sampai benar-benar kering.

\section{Tahap Karbonasi (pengarangan)}

Tongkol jagung kering dimasukkan ke dalam drum pengarangan disusun sedemikian rupa hingga hampir penuh, drum ditutup rapat kemudian api dinyalakan melalui lubang ventilasi/tempat bagian dasar drum, proses pembakaran pada suhu $360{ }^{\circ} \mathrm{C}$ dibiarkan sehingga semua bahan habis terbakar. Setelah dingin dilakukan pembongkaran dan arang yang dihasilkan dipisahkan dari abu sisa pembangkaran untuk proses lebih lanjut.

\section{Tahap Pembuatan Serbuk Arang}

Arang dari proses karbonasi dihaluskan dengan menggunakan blender sampai membentuk serbuk kemudian disaring menggunakan ayakan. 


\section{Tahap Aktivasi fisika dan aktifasi Kimia}

Aktifasi arang aktif sesuai dengan metode yang digunakan oleh (Budiono, 2010) yang telah dimodifikasi. Sebanyak 100 gram serbuk arang diaktifasi secara fisika dan kimia. Untuk aktifasi secara fisika sebanyak 100 gram serbuk arang tongkol jagung dimasukan kedalam gelas kimia kemudian dipanaskan pada suhu $150{ }^{\circ} \mathrm{C}$ selama 2 jam. Setelah itu didinginkan dalam desikator. Sedangkan untuk aktifasi secara kimia, sebanyak 100 gram arang tongkol jagung hasil aktifasi secara fisika direndam dalam $200 \mathrm{~mL}$ larutan $\mathrm{HCl} 1 \mathrm{M}$ selama 24 jam. Kemudian campuran tersebut disaring dengan mengunakan kertas saring dan dicuci dengan aquades sampai pH netral. Selanjutnya dikeringkan dalam oven pada suhu $100{ }^{\circ} \mathrm{C}$ selama 2 jam.

\section{Uji Adsorpsi}

Sebanyak $20 \mathrm{~mL}$ larutan warna ungu $100 \mathrm{ppm}$ dimasukan kedalam erlenmeyer kemudian ditambahkan $0 ; 0,2 ; 0,4 ; 0,6 ; 0,8$ dan 1 gram serbuk arang aktif. Campuran tersebut diaduk menggunakan magnetic stirrer selama 10 menit. Dilanjutkan dengan penyaringan menggunakan kertas saring. Fitrat yang dihasilkan diukur absorbansinya dengan menggunakan spektrofotometer UV-Vis pada panjang gelombang $664 \mathrm{~nm}$ (Bharathi, 2013).

\section{HASIL DAN PEMBAHASAN}

\section{Preparasi Sampel Tongkol Jagung (Zea mays L.)}

Tongkol jagung yang berumur 100-130 hari dipotong menjadi bagian-bagian kecil supaya tongkol jagung bisa cepat terbakar kemudian dibersihkan dengan cara dicuci pada air mengalir untuk menghilangkan partikel-partikel pengotor yang melekat pada permukaan tongkol jagung setelah dicuci kemudian dikeringkan dibawah sinar matahari selama 2-3 hari (Alfiany. 2013), hal ini dilakukan untuk mengurangi kadar air pada tongkol jagung agar cepat mengering sampai kedalam supaya bisa dibakar.

\section{Tahap Karbonasi}

Arang dari tongkol jagung didapatkan dari proses karbonasi (pembakaran) Karbonasi merupakan tahapan yang harus dilakukan untuk mendapatkan arang yang diinginkan dengan cara pembakaran dengan menggunakan drum yang dibagian bawahnya dilubangi sampai 20 lubang agar api bisa masuk melalui lubang-lubang yang dibuat sedangkan pada bagian atas drum diberi lubang untuk menjadi fertilasi udara lalu serpihan tongkol jagung yang sudah kering dimasuka dalam drum dan dibakar pada suhu $360^{\circ} \mathrm{C}$ sampai suhu $400{ }^{\circ} \mathrm{C}$. Kemudian setelah itu arang dipisahkan dari abu. Kemudian arang hasil pembakaran diblender supaya halus kemudian diayak sampai menjadi serbuk arang.

\section{Tahap aktivasi}

Tahap dimana serbuk arang ditimbang sebanyak 100 gram kemudian proses pembuatan arang aktif yang bertujuan untuk membuka, menambah atau mengembangkan volume pori dan memperbesar diameter pori yang telah terbentuk pada proses karbonisasi. Melalui proses aktivasi arang aktif akan memiliki daya adsorpsi yang semakin meningkat, karena arang aktif hasil karbonisasi biasanya masih mengandung zat yang masih menutupi pori-pori permukaan karbon aktif. Pada proses aktivasi arang aktif akan mengalami 
perubahan sifat, baik fisika maupun kimia sehingga dapat berpengaruh terhadap daya adsorpsi (Budiono, 2010).

Aktivasi fisika dengan cara memanaskan serbuk arang dalam oven pada suhu $150{ }^{\circ} \mathrm{C}$ selama 2 jam supaya permukaan serbuk arang pori-porinya terbuka agar daya serapnya besar dan dapat dijadikan penyerap atau adsorpsi yang baik, selanjutnya pada tahap aktivasi kimia serbuk arang hasil aktivasi fisika diberikan perlakuan kembali dengan merendam serbuk arang dengan $\mathrm{HCl} 1 \mathrm{M}$ sebanyak $200 \mathrm{~mL}$ selama 24 jam, hal ini dilakukan agar serbuk arang bisa menjadi serbuk arang aktif Kemudian setelah sampai 24 jam rendaman di saring dan dicuci dengan aquades sampai $\mathrm{pH}$ netral, langkah selanjutnya residu dikeringkan setelah pencucian lalu di saring menggunakan kertas saring hasil dari seerbuk arang yang masih basah akan dikeringkan dalam oven selama 2 jam pada suhu 100 ${ }^{\circ} \mathrm{C}$ kemudian arang didingankan dalam desikator dan diperoleh arang yang telah teraktivasi (Budiono, 2010).

Pelarut $\mathrm{HCl} 1 \mathrm{M}$ dibuat dari $\mathrm{HCl}$ pada konsetrasi $37 \%$ yang diencerkan dengan menambahkan aquades kedalam erlemeyer ukura $250 \mathrm{~mL}$. Asam klorida $(\mathrm{HCl})$ sebagai zat aktivator kimia yang bersifat higroskopis yang dapat mengurangi kadar air pada arang aktif yang dihasilkan. Dibandingan dengan aktivator lainya seperti $\mathrm{H}_{2} \mathrm{SO}_{4}$ dan $\mathrm{HNO}_{3}$, arang aktif yang diaktivasi $\mathrm{HCl}$ memiliki daya serap iod yang lebih baik karena $\mathrm{HCl}$ lebih dapat melarutkan pengotor sehinga pori-pori lebih banyak terbentuk dan proses penyrapan adsorben menjadi lebih maksimal (Alfiany, 2013).

\section{Adsorpsi Zat Warna Ungu}

Tahap awal adsorpsi yang dilakukan dalam penelitian ini adalah adsorpsi zat warna sintetis ungu dengan variasi massa adsorben divariasikan menjadi 0 gram, 0,2 gram, 0,4 gram, 0,6 gram, 0,8 gram dan 1 gram. Massa adsorben merupakan salah satu faktor yang mempengaruhi hasil ekstraksi, karena perbedaan antara massa adsorben yang satu dengan yang lain menyebapkan perbedaan sifat adsorpsi pelarut yang berdampak pada hasil adsorpsi yang didapatkan. Banyak atau sedikitnya adsorpsi tergantung pada jumlah massa yang digunakan. Adsorpsi (penyerapan) akan lebih banyak pada zat warna yang diberi banyak serbuk arang aktif. Adapun massa adsorben serbuk arang aktif divariasikan menjadi divariasikan menjadi 0 gram, 0,2 gram, 0,4 gram, 0,6 gram, 0,8 gram dan 1 gram. Faktorfaktor lain yang mempengaruhi hasil adsorpsi meliputi waktu adsorpsi, suhu adsorpsi, metode adsorpsi, ukuran bahan padat yang diadsorpsi.

Berdasarkan hasil penelitian dapat dilihat bahwa larutan warna sintetis ungu 100 ppm semakin banyak jumlah arang aktif yang dimasukan maka daya serap dari zat warna sintetis wantex ungu semakin besar pula adsorpsinya. Dapat disimpulkan bahwa variasi massa adsorben berpengaruh terhadap hasil adsorpsi zat warna sintetis wantex ungu dengan menggunakan metode adsorpsi.

Pada gambar 1 menunjukan bahwa secara garis besar harus terjadi peningkatan adsorpsi (penyerapan) selama ditambahkan jumlah massa yang semakin banyak massa yang ditambahkan kedalam larutan zat warna maka adsorpsi (penyerapan) yang terjadi akan semakin besar. Hasil peningkatan terjadi peningkatan adsorpsi (penyerapan) dari nilai absorbansi yang didapatkan dari larutan zat warna ungu tanpa dicampur dengan arang aktif yaitu sebesar $(A=0.985)$ kemudian ditambahkan 0,2 gram serbuk arang aktif maka larutan zat warna wantex berkurang menjadi $(A=0.901)$ selanjutnya ditambahkan 0,4 gram serbuk 
arang aktif maka daya serapnya makin besar dengan nilai adsorbansi $(A=0.746)$ kemudian semakin banyak penambahan jumlah massa adsorben maka daya serap larutan zat warna ungu akan semakin besar pula namun dari hasil yang didaptkan pada penambahan massa 0.6 gram mengalami penyerapan yang sedikit dibanding dengan 0,4 gram dengan nilai absorbansinya $(A=0.761)$ begitupun dengan penambahan serbuk arang aktif 0,8 gram terjadi sedikit penyerapan dengan nilai absorbansi $(A=0,771)$ dalam hal ini dikarenakan pada saat penelitian terjadi kesalahan pada saat pengadukan dengan menggunakan magnetic stirer waktu yang digunakan kurang dari 10 menit dan saat penyaringan tidak didiamkan sebentar langsung disaring.

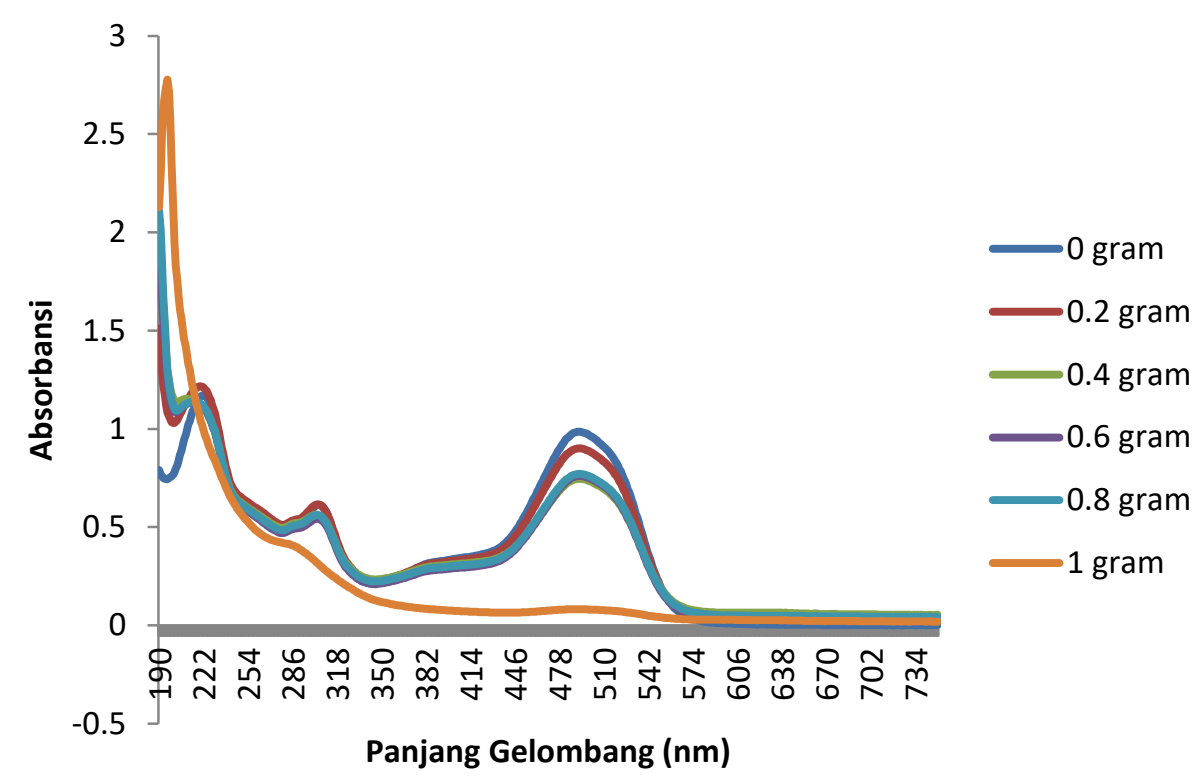

Gambar 1. pengaruh jumlah adsorben terhadap adsorpsi zat warna sintetis

Terjadi peningkatan adsorpsi atau penyerapan yang sangat besar pada saat menambahkan serbuk arang aktif sebanyak 1 gram dengan nilai adsorbansi $(A=0.082$ ) sesuai dengan penelitian yang dilakukan oleh (Ahmad. 2009) yang mengunakan variasi massa adsorben untuk mengadsorpsi zat warna, kondisi optimum variasi massa yang diperoleh 0,10 gram dengan perolehan persen adsorpsi sebesar 97,00\% karena pada massa bisa di simpulkan bahwa semakin banyak jumlah massa yang diberika maka daya adsorpsi pada zat warna itu akan makin banyak dan bahkan zat warna sintetis akan menghilang. Pada hasil menggunakan Analisis spektra data yang dihasilkan yaitu Pada rentang panjang gelombang 390-640 nm terlihat dengan adanya penambahan adsorben sebanyak $1 \mathrm{gram}$, warna dari pewarna sintetis semakin memudar. Hal ini menandakan bahwa semakin banyak massa adsorben ynag ditambahkan maka pewarna sintetis semakin teradsorpsi (terserap).

\section{KESIMPULAN}

Berdasarkan dari data hasil penelitian yang telah dianalisis dan dibahas dapat diambil simpulan bahwa serbuk arang aktif dari tongkol jagung sangat cocok untuk dijadikan arang aktif karena terbukti bahwa serbuk arang aktif untuk dijadikan adsorben mampu mengadsorpsi zat warna sintetis orange pada variasi massa adsorben 0,2 gram, 0,4 gram, 
0,6 gram, 0,8 gram dan 1 gram. Pada variasi massa adsorben terbukti bahwa semakin banyak serbuk arang aktif yang digunakan maka daya serapnya semakin besar pada zat warna sintetis orange panjang gelombang maksimum $\lambda_{\text {maks }} 493 \mathrm{~nm}$ dengan nilai adsorbansi $(A=0,082)$.

\section{UCAPAN TERIMAKASIH}

Penulis mengucapkan terimakasih kepada semua pihak yang telah membantu baik moril maupun materil dalam penyelesaian artikel ini.

\section{DAFTAR PUSTAKA}

Alfiany, H., B. Syaiful, dan Nurakhirawan. 2013. Kajian Penggunaan Arang Aktif Tongkol Jagung Sebagai Absorben Logam Pb dengan Beberapa Aktivator Asam. Jurnal Natural Science, 2 (3): 75-86.

Ahmad, R. 2009, Study In Adsorpsions Of Crystal Viole Dan From Aqueos Solations Onto Ciniferou Pinus Bark Powder (CPNP), J Hajard mater.

Bharathi, K. S. and S. T. Ramesh. 2013. Removal of dyes using agricultural waste as lowcost adsorbents: a review. Journal of Applied Water Science. pp. 773- 790.

Budiono, A, Suhartana, Gunawan. 2010. Pengaruh Aktivasi Arang Tempurung Kelapa Asam Sulfat dan Fosfat untuk Adsorpsi Fenol. Laboratorium Kimia Anorganik, Laboratoium Kimia Nalitik.Jursan Kimia .Universitas Indonesia Diponogoro

Patel, R. dan S. Surest. 2008. Kinetic And Equlilelibrium Studies On The Biosorption Of Reactive Black 5 Dye By Asperqillus Foutidus.Bioresour Tehnology.Pp.51-5

Pambayun, G. S., Y. E. Y. Remigius, M. Rachimoellah, dan M. M. P. Endah. 2013. Pembuatan Karbon Aktif dari Arang Tempurung Kelapa dengan Aktivator $\mathrm{ZnCl} 2$ Dan Na2CO3 Sebagai Adsorben Untuk Mengurangi Kadar Fenol Dalam Air Limbah. Jurnal Teknik Pomits. Vol. 2, No. 1

Patel, R. and S. Suresh. 2008. Kinetic and equilibrium studies on the biosorption of reactive black 5 dye by Aspergillus foetidus. Bioresour Technology. pp.51-58.

Purwanto, D. 2011. Arang dari Limbah Kelapa Sawit (Elaeis guineensis Jacq). Badan Penelitian dan Pengembangan Kehutanan. Bogor. Jurnal Penelitian Hasil Hutan. Vol. 29, No.

Ruslan, K. W. (2013). Study of physico-chemical properties of Si [O. sub. 2]-[Al. sub. 2][O. sub. 3]/bentonite nanocomposite: thermal and acid stability. International Journal of Applied Chemistry, 9(1), 15-36.

Sallau, B., A. Aliyu, Salihu and S. Ukuwa. 2012. Biosorption of Chromium (VI) from Aqueous Solution by Corn Cob Powder. International Journal of Environmrnt and Bioenergy, 4(3): $131-140$

Sudarja dan N, Caroko. 2012. Kaji Eksperimental Efektifitas Penyerapan Limbah Cair Industri Batik Taman Sari Yogyakarta Menggunakan Arang Aktif Mesh 80 dari Limbah Gergaji Kayu Jati. Jurnal Ilmiah Semesta Teknika. Vol. 14, hal. 50-58

Surest, A.H. 2008. Pengaruh Suhu, Konsentrasi Zat Aktivator dan Waktu Aktivasi terhadap Daya Serap Karbon Aktif dari Tempurung Kemiri. Jurnal Teknik Kimia.2(15)

Suhartati, T. 2017. Dasar-Dasar Spektrofotometri UV-Vis dan Spektrometri Massa untuk Penentuan Struktur Senyawa Organik. Lampung: Anugrah Utama Raharja. 